\title{
Projected End-of-Century Changes in the South American Monsoon in the CESM Large Ensemble ${ }^{\mathscr{O}}$
}

\author{
Ana Claudia Thome Sena And Gudrun Magnusdottir \\ University of California, Irvine, Irvine, California
}

(Manuscript received 23 August 2019, in final form 19 June 2020)

\begin{abstract}
Projected changes in the South American monsoon system by the end of the twenty-first century are analyzed using the Community Earth System Model Large Ensemble (CESM-LENS). The wet season is shorter in LENS when compared to observations, with the mean onset occurring 19 days later and the mean retreat date 21 days earlier in the season. Despite a precipitation bias, the seasonality of rainfall over South America is reproduced in LENS, as well as the main circulation features associated with the development of the South American monsoon. Both the onset and retreat of the wet season over South America are delayed in the future compared to current climate by 3 and 7 days, respectively, with a slightly longer wet season. Central and southeastern Brazil are projected to get wetter as a result of moisture convergence from the strengthening of the South Atlantic low-level jet and a weaker South Atlantic subtropical high. The Amazon is projected to get drier by the end of the century, negatively affecting rain forest productivity. During the wet season, an increase in the frequency and intensity of extreme precipitation events is found over most of South America, and especially over northeastern and southern Brazil and La Plata. Meanwhile, during the dry season an increase in the maximum number of consecutive dry days is found over northeastern Brazil and the northern Amazon.
\end{abstract}

\section{Introduction}

South America's climate has well characterized wet and dry seasons due to the influence of the South American monsoon system (SAMS; Zhou and Lau 1998; Vera et al. 2006; Marengo et al. 2012). The onset of this regime is characterized by the reversal of the anomalous low-level moisture flux over central South America. During austral spring, the trade winds over the tropical Atlantic intensify and enhance the moisture influx to tropical continental South America. This moisture is recycled over the Amazon and eventually brought to the continental and southeastern South America by a northwesterly low-level jet, known as the South American low-level jet (SALLJ). Meanwhile, the South Atlantic subtropical high (SASH) over the ocean basin weakens and moves west, increasing moisture influx from the South

Supplemental information related to this paper is available at the Journals Online website: https://doi.org/10.1175/JCLI-D-190645.s1.

Corresponding author: Ana Claudia Thome Sena, athomese@ uci.edu
Atlantic into southeastern Brazil (Raia and Cavalcanti 2008). In austral fall, the low-level wind anomaly reverses, which marks the end of the SAMS wet season.

The presence of the Amazon rain forest over the region is crucial for SAMS development. Latent heat released by convection fed by Amazon evapotranspiration forms a pressure gradient that strengthens the trade winds, providing the conditions for SAMS initiation (Wright et al. 2017; Gandu and Silva Dias 1998). Figueroa et al. (1995) argue that the latent heat released over the Amazon leads to the atmospheric disturbances that generate and maintain a northwest-southeastdirected convergence zone, known as the South Atlantic convergence zone (SACZ). The SACZ is the main source of precipitation and extreme rainfall in southeastern Brazil (Carvalho et al. 2002, 2004), and its failure may cause drought in the most populated region of Latin America (Coelho et al. 2016). The Amazon is also important for the SALLJ development. This raises concerns about the consequences of deforestation over the Amazon on the climate over tropical and subtropical South America, especially its water cycle. A recent modeling study (Boers et al. 2017) suggests that there is a tipping point on deforestation that, once crossed, 
shuts down the SALLJ, drying continental South America.

Previous studies found that the Amazon is projected to get drier by the end of the century (Lehner et al. 2017; Cook et al. 2014). In the present climate, longer and more intense dry seasons reduce atmospheric water vapor content over the southern Amazon during the transition to the wet season (Agudelo et al. 2019). This affects moisture recycling over the area. Meanwhile, the SALLJ is intensified, but it carries less moisture to the center of South America (Collini et al. 2008). In contrast, in this work we find that the end-of-the-century climate is marked by increased atmospheric moisture content through thermodynamic effects. We find that in a warmer climate, evaporation over the Atlantic ocean makes more moisture available to be carried by the trade winds and SALLJ.

In this study, we analyze how the SAMS wet-season length and precipitation intensity over South America are projected to change by the end of the twenty-first century using the Community Earth System Model (CESM) Large Ensemble Simulations (LENS; Kay et al. 2015). LENS provides valuable means to isolate anthropogenic influences from internal variability. Changes in the intensity and frequency of rainfall extremes are also analyzed. By analyzing multiple realizations from the same climate model, we can infer the role of model internal variability in the projections.

Previous studies have shown different results regarding the SAMS length and intensity in the future, depending on the model analyzed and methodology used (Pascale et al. 2019). Over the Amazon, studies have shown both a projected lengthening of the wet season (Jones and Carvalho 2013) and a lengthening of the dry season (Boisier et al. 2015; Fu et al. 2013), or no significant changes in the onset, retreat, and length of the SAMS (Bombardi et al. 2009).

Extreme events are also projected to become more frequent in South America, and the Amazon is especially responsive to those changes ( $\mathrm{Xu}$ et al. 2019). Drought events over the Amazon are projected to become more frequent and widespread by the end of the twenty-first century under climate change scenarios (Duffy et al. 2015). Drought events are known to cause a net carbon loss due to tree mortality (Feldpausch et al. 2016; Lewis et al. 2011; Phillips et al. 2009; Mahli et al. 2009). This has lasting effects for years to come (Yang et al. 2018) in the present climate, raising concerns about reduced Amazon productivity in the future due to meteorological drought. Meanwhile, extreme wet events are expected to increase due to the intensification of the hydrological cycle, both over wet and dry areas (Donat et al. 2016). This trend is also seen in South America with extreme wetness projected to become more

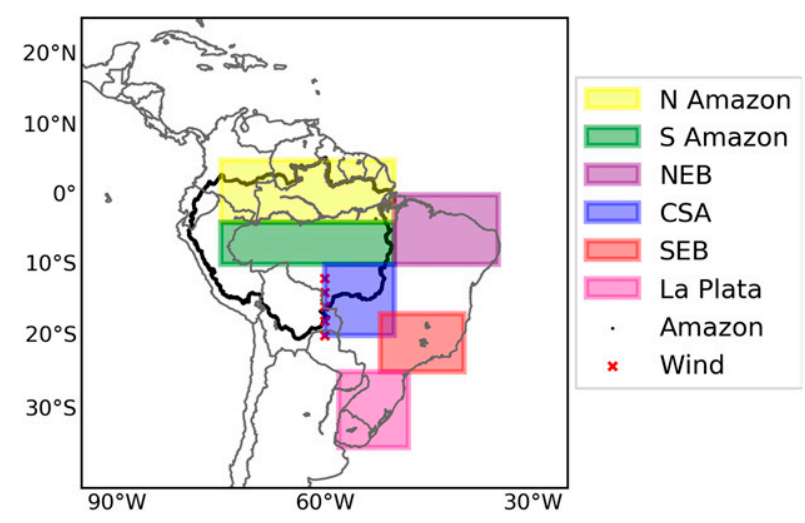

FIG. 1. Spatial domain covered by each of the areas: northern Amazon (N Amazon), southern Amazon (S Amazon), northeastern Brazil (NEB), central South America (CSA), southeastern Brazil (SEB), and La Plata Basin (La Plata). The cross section of central South America where the wind is used to calculate SAMS onset date is also shown (red $\times$ symbols), as well as the Amazon Basin (black heavy contour).

frequent over the Amazon in a RCP8.5 scenario (Duffy et al. 2015). An increase in wet extreme events over South America has already been noted in observations, but the attribution of these trends to climate change is difficult due to the connection between rainfall over this area and long-term modes of climate variability, such as the interdecadal Pacific oscillation, Pacific decadal oscillation, and Atlantic multidecadal oscillation (Grimm 2019; Marengo et al. 2013; Skansi et al. 2013; Haylock et al. 2006).

Our objective is to examine how circulation features associated with rainfall in the South American monsoon region are projected to change in a warmer climate using multiple realizations of the same global climate model. This allows us to isolate the internal variability from the anthropogenic signal. We focus on the changes in total rainfall, as well as wet-season onset and retreat dates at the end of the twenty-first century. Since South America includes areas from the equatorial region to the subtropics and extratropics, representing different climates, the area is divided into six domains (Fig. 1): the northern Amazon (N Amazon), southern Amazon (S Amazon), northeastern Brazil (Nordeste), central South America (CSA), southeastern Brazil (SEB), and La Plata Basin (La Plata). For each area, we analyze changes in the total precipitation during the wet and dry seasons, as well as changes in the frequency and intensity of extreme wet and dry events.

This paper is organized as follows. Section 2 describes the LENS and introduces the methodology and data we used in the analysis. Section 3 describes the results obtained for the projected changes in SAMS length and 
rainfall over South America, as well as changes in extreme events of precipitation. Finally, section 4 concludes by summarizing the findings presented in this paper.

\section{Data and methods}

\section{a. Data}

CESM LENS (Kay et al. 2015) consists of 40 realizations of the same climate model, the CESM 1.1 fully coupled global climate model. LENS uses the Community Atmospheric Model, version 5.2 (CAM 5.2), as its atmospheric component and the Community Land Model, version 4.0 (CLM 4.0), as its land component. A random round-off error in the surface temperature field was introduced in each ensemble member that was branched off in 1920 . The spatial resolution is $1^{\circ} \times 1^{\circ}$. Each simulation is performed with historical greenhouse gas and aerosol forcing from 1920 to 2005, and with the representative concentration pathway 8.5 (RCP8.5) emissions scenario from 2006 to 2100 .

LENS performance over the region of the South America monsoon for the historical period is compared with satellite-based observations and the European Centre for Medium-Range Weather Forecasts (ECMWF) interim reanalysis (ERA-Interim). The ERA-Interim (Dee et al. 2011) data are available daily from 1979 to the present at a $0.75^{\circ}$ spatial resolution.

Rainfall from the Climate Hazards Group Infrared Precipitation with Station (CHIRPS; Funk et al. 2015) data was used in this project. CHIRPS estimates rainfall over land using geostationary satellite's infrared measurement along with rainfall measured at stations. It is available daily between 1981 and the present at a $0.05^{\circ}$ spatial resolution between $50^{\circ} \mathrm{N}$ and $50^{\circ} \mathrm{S}$.

\section{b. Data analysis}

SAMS onset is defined as the first day with precipitation greater than $4 \mathrm{~mm}$ day $^{-1}$ over the Amazon (depicted by the heavy black contour in Fig. 1), persisting for at least two-thirds of the following 40 days, and associated with westerly $850-\mathrm{hPa}$ wind over central South America $\left(10^{\circ}-20^{\circ} \mathrm{S}, 60^{\circ} \mathrm{W}\right.$; the cross section is highlighted in Fig. 1). The first date when these conditions are no longer met is defined as the SAMS retreat (Gan et al. 2005). Both precipitation and wind data are smoothed with a 5-day running mean prior to analysis. SAMS onset, retreat, and length are computed for each year and each ensemble member in LENS. These quantities are computed from 1981 to 2017 in observations, using ERA-Interim $850-\mathrm{hPa}$ wind and precipitation from CHIRPS.
We assess the ability of LENS to reproduce the rainfall over South America by comparing it to CHIRPS and ERA-Interim. We analyze three main rainfall characteristics:

- The model bias in precipitation. Subtracting the ensemble mean, annual average precipitation in LENS over each area in South America from the annual average precipitation in CHIRPS in the same area and over a common time period 19812017 (corresponding to availability of observational product). When comparing to ERA-Interim, we use the period 1979-2017.

- Monthly precipitation anomalies over each area of South America (subtracting the annual mean precipitation over the area), again referring to the period of each product.

- The spatial distribution of precipitation anomalies averaged over the peak of the wet season (December to February) and the peak of the dry season (June to August).

We analyze the effect of SAMS onset on rainfall over South America by comparing to observations the amount and spatial distribution of precipitation for a composite from LENS during the 15 days prior to SAMS onset, and 5 to 20 days after SAMS onset. In this analysis, we remove the annual cycle by subtracting the average precipitation for each calendar day.

Projected changes in South American hydroclimate are defined as the difference between a 31-yr period in the late twenty-first century (2070 to 2100; hereafter "future") and a 31-yr period in the late twentieth century (1970 to 2000; hereafter "present"). Two methods were used in order to determine the significance of the response: a two-tailed Student's $t$ test was used to determine the significance of the ensemblemean response, and a two-sample KolmogorovSmirnov test (KS test) was performed in order determine the significance of the changes in the distribution of events.

To determine the changes in the source of the moisture in the region we calculated the vertically integrated moisture flux (MF) from 1000 to $700 \mathrm{hPa}$, defined as

$$
\mathbf{M F}(\lambda, \phi, t)=\frac{1}{g} \int_{P_{s}}^{P} q(\lambda, \phi, p, t) \mathbf{V}(\lambda, \phi, p, t) d p,
$$

where $g$ is the acceleration of gravity, $q$ is the specific humidity at each level, and $\mathbf{V}$ is the horizontal wind velocity.

We analyzed changes in precipitation, net primary productivity (NPP) and surface latent heat flux for each area introduced in Fig. 1. 
DJF

(a) CHIRPS

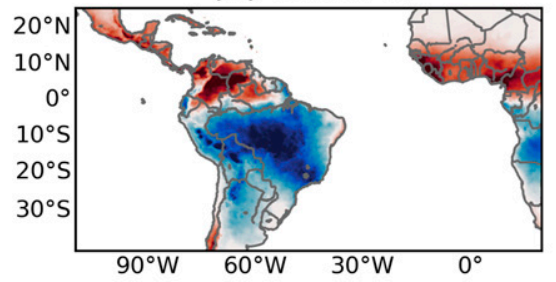

(b) LENS

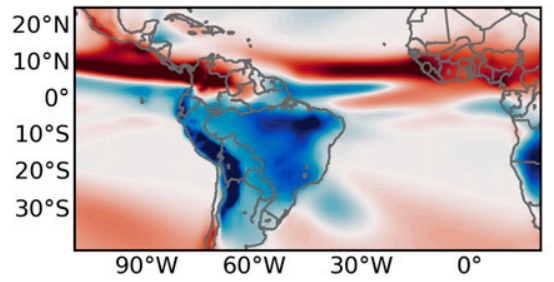

(c) ERA interim

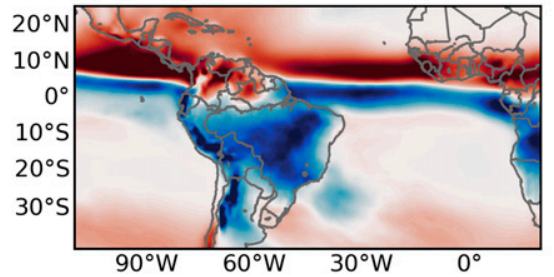

JJA

(d) CHIRPS

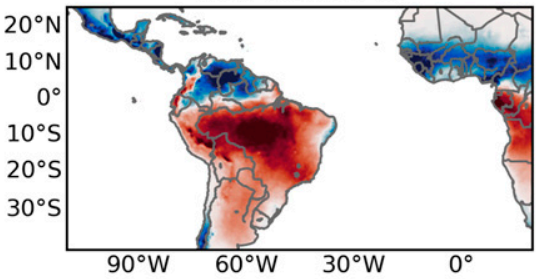

(e) LENS

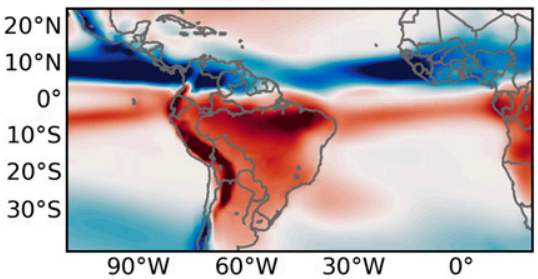

(f) ERA interim

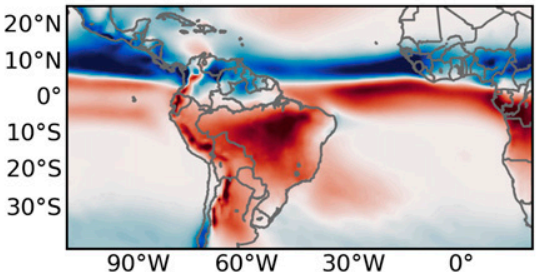

4.4

3.3

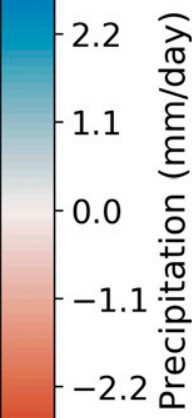

$-3.3$

FIG. 2. Mean precipitation (in $\mathrm{mm} \mathrm{day}^{-1}$ ) averaged over December-February (DJF) minus the mean annual precipitation for (a) 1981-2017 in CHIRPS; (b) the ensemble mean, 1920-2017 in LENS; and (c) 1979-2017 in ERA-Interim. Also shown is the mean precipitation averaged over June-August (JJA) minus the mean annual precipitation for the same period (d) in CHIRPS, (e) for the ensemble mean in LENS, and (f) in ERAInterim.

We analyzed the contribution of dynamic, thermodynamic, and evaporation changes to the projected precipitation based on the linearized moisture budget equation (Trenberth and Guillemot 1995). We define the contribution of each term to the response to climate change following Endo and Kitoh (2014). Each term is defined by

$$
\begin{gathered}
\delta P=\delta E+\delta \mathrm{TH}+\delta \mathrm{DY}+\mathrm{Res}, \\
\delta \mathrm{TH}=-\frac{1}{g \rho} \int_{0}^{1000 \mathrm{hPa}} \nabla \cdot\left(\mathbf{V}_{\text {present }} \delta q\right) d p, \\
\delta \mathrm{DY}=-\frac{1}{g \rho} \int_{0}^{1000 \mathrm{hPa}} \nabla \cdot\left(q_{\text {present }} \delta \mathbf{V}\right) d p,
\end{gathered}
$$

where $\delta$ represents the difference between the term in future and present climate, $\rho$ is the density of water, $P$ is the precipitation, $E$ is the evaporation, TH is the thermodynamic term, and DY is the dynamic effect. In our analysis, the residual (Res) includes the contribution of the changes in the transient system.

For each of the areas considered, extreme events of precipitation were analyzed using two main metrics:

- the number of consecutive dry days, defined as the maximum number of consecutive days with areaaveraged precipitation below $1 \mathrm{~mm} \mathrm{day}^{-1}$ for each year and ensemble member; and

- the maximum daily precipitation, defined as the magnitude of the maximum area-averaged rainfall event for each year and each ensemble member.

The maximum daily precipitation was analyzed by fitting a generalized extreme value distribution (GEV), used to determine the changes in the wet events extremes. This distribution is the most suitable to determine changes in extreme events, and its probability density function is defined as in Kotz and Nadarajah (2010), 

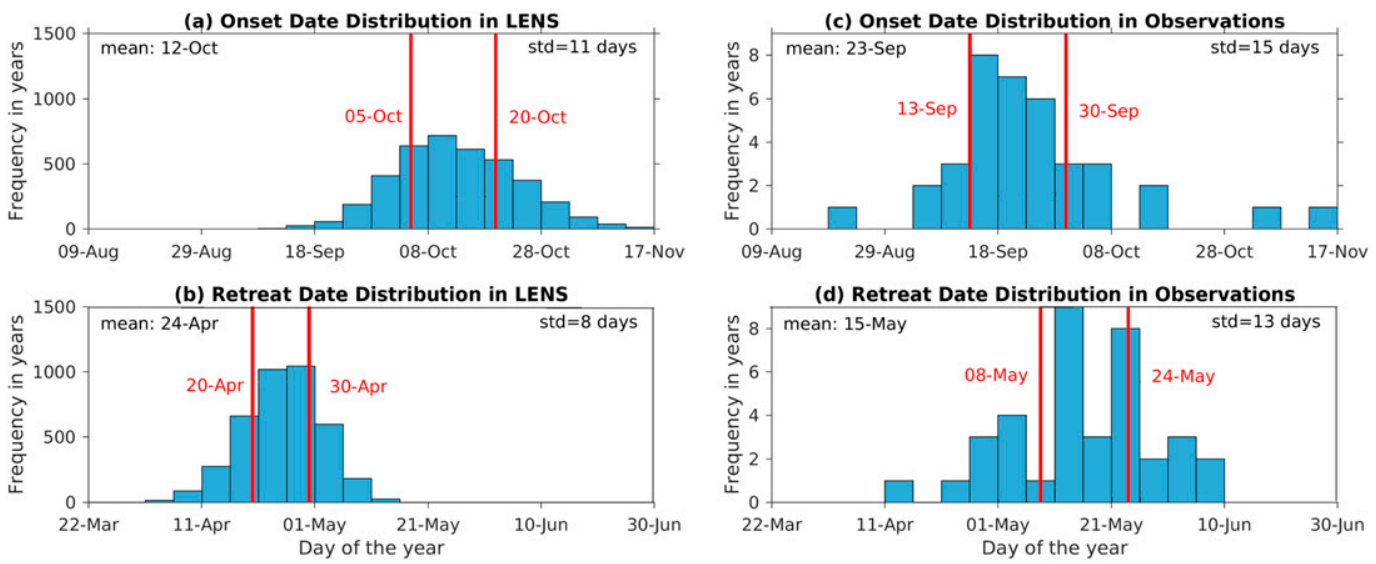

FIG. 3. (a) The distribution of SAMS onset date for 1920-2017 in all 40 ensemble members of LENS. (b) As in (a), but for SAMS retreat date. (c) SAMS onset date distribution between 1981 and 2017 using CHIRPS precipitation and ERA-Interim 850-hPa wind. (d) As in (c), but for retreat date. For each plot, the 25th and 75th percentiles are shown in red. The mean of each distribution is shown in the top left. Their standard deviation is shown in the top right. Each bin corresponds to 5 days.

$$
\operatorname{pr}(x)=\left\{\begin{array}{cc}
\exp \left\{-\left[1+\xi\left(\frac{x-\mu}{\sigma}\right)\right]\right\}^{-1 / \xi} \frac{1}{\sigma}\left[1+\xi\left(\frac{x-\mu}{\sigma}\right)\right]^{-1 / \xi-1}, & \xi \neq 0 \\
\exp \left[-\exp \left(-\frac{x-\mu}{\sigma}\right)\right] \frac{1}{\sigma} \exp \left[-\left(\frac{x-\mu}{\sigma}\right)\right], & \xi=0
\end{array},\right.
$$

where $\mu$ is the location parameter, $\xi$ is the shape parameter, and $\sigma$ is the scale parameter of the distribution. A GEV was fitted to the maximum daily precipitation for the present and future climate. These results are discussed in section $3 \mathrm{c}$.

\section{Results}

\section{a. The representation of SAMS in LENS}

We examine the following characteristics of the SAMS: the seasonal precipitation anomaly and its spatial distribution, SAMS onset and retreat dates, and

TABLE 1. Mean and standard deviation of the precipitation bias (in $\mathrm{mm} \mathrm{day}^{-1}$ ) between 1981 and 2017 for each region analyzed, calculated as the difference between LENS and CHIRPS, LENS and ERA-Interim, and ERA-Interim and CHIRPS.

\begin{tabular}{|c|c|c|c|c|c|c|}
\hline & \multicolumn{2}{|c|}{$\begin{array}{l}\text { LENS - } \\
\text { CHIRPS }\end{array}$} & \multicolumn{2}{|c|}{$\begin{array}{l}\text { LENS - ERA- } \\
\text { Interim } \\
\end{array}$} & \multicolumn{2}{|c|}{$\begin{array}{c}\text { ERA-Interim - } \\
\text { CHIRPS }\end{array}$} \\
\hline & Mean & Std dev & Mean & Std dev & Mean & Std dev \\
\hline N Amazon & -1.65 & 0.45 & -1.53 & 0.64 & -0.12 & 0.50 \\
\hline S Amazon & -1.70 & 0.37 & -2.19 & 0.49 & 0.49 & 0.47 \\
\hline Nordeste & 1.39 & 0.58 & 0.29 & 0.80 & 1.10 & 0.41 \\
\hline CSA & -1.27 & 0.28 & -1.23 & 0.41 & -0.04 & 0.39 \\
\hline SEB & -0.91 & 0.37 & -0.36 & 0.40 & -0.55 & 0.22 \\
\hline La Plata & -1.36 & 0.68 & -0.64 & 0.51 & -0.72 & 0.43 \\
\hline
\end{tabular}

wet-season length in LENS and observations. The ensemble mean of LENS captures the spatial distribution of the rainfall anomaly during both the peak of the SAMS (DJF) and during the peak of the dry season (JJA), as shown in Fig. 2. We show precipitation from ERAInterim as well as for CHIRPS as the latter is limited to land areas only. The spatial pattern of rainfall anomalies in ERA-Interim is similar to the satellite products (Fig. S1 in the online supplemental material). During the peak of the wet season, the ensemble mean of LENS (Fig. 2b) shows an increase in rainfall over South America that is directed as a northwesternsoutheastern band of precipitation anomaly in Brazil, extending to the southern Atlantic Ocean. This suggests that the main characteristics of SACZ are reproduced by LENS. Although the ITCZ over the eastern portion of the Atlantic Ocean is weaker in LENS than in ERA-Interim (Fig. 2c), the increase in rainfall over the western tropical Atlantic and northeastern Brazil is captured by the model. During the peak of the dry season, rainfall is reduced over most of South America. The area where the SACZ generally occurs is dry both in the ensemble mean of LENS (Fig. 2e) and in observations (Figs. 2d,f). In JJA, the ensemble mean of LENS is dryer than observations over the equatorial South America, particularly over Colombia (Figs. S2d,e). 
(a) N Amazon

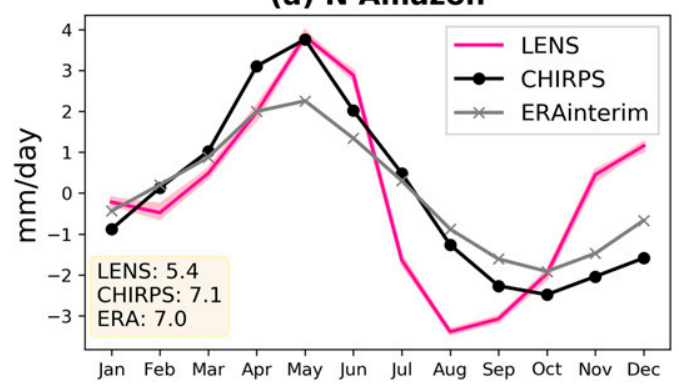

(c) Nordeste

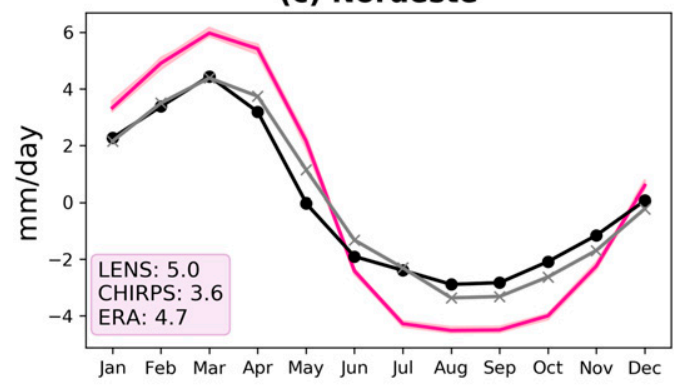

(e) SEB

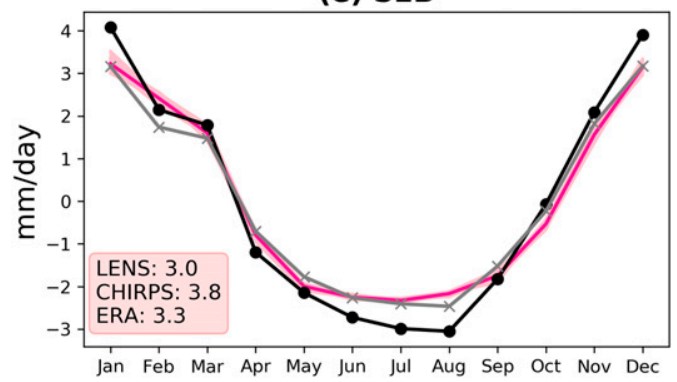

(b) S Amazon

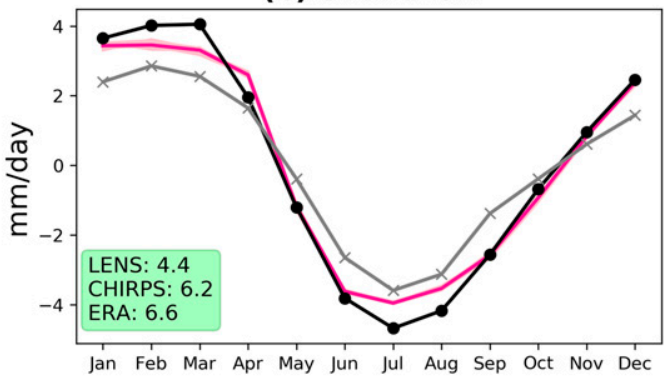

(d) CSA

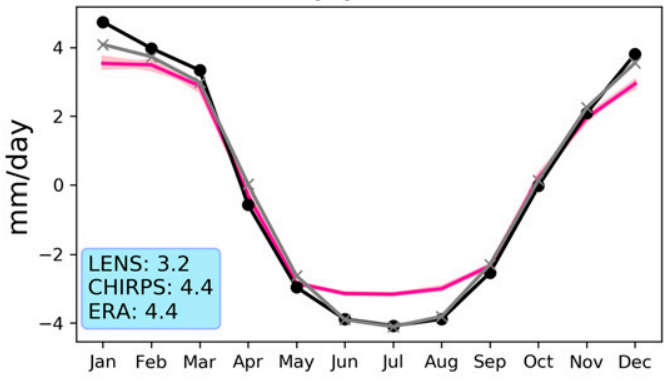

(f) La Plata

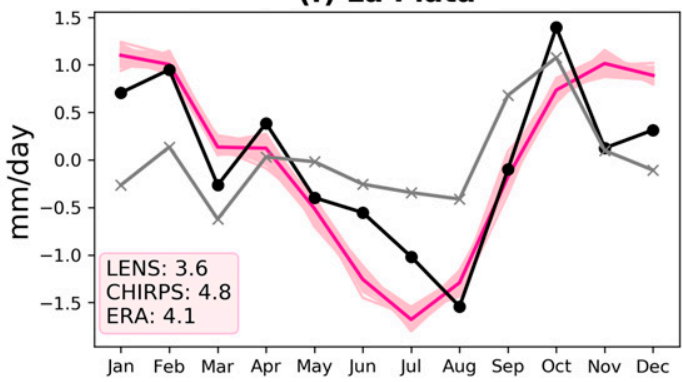

FIG. 4. Monthly mean precipitation (in $\mathrm{mm} \mathrm{day}^{-1}$ ) minus the mean annual precipitation over (a) N Amazon, (b) S Amazon, (c) Nordeste, (d) CSA, (e) SEB, and (f) La Plata. The mean precipitation is computed for 1981-2017 in CHIRPS (in black), for 1979-2017 in ERA-Interim (in gray), and for 1920-2017 in LENS (in pink). The ensemble mean in LENS is highlighted by a bold contour. The mean annual precipitation (in mm day ${ }^{-1}$ ) for each product is shown in the bottom left of each panel.

Consistent with observations, the wet season in LENS starts during the austral spring and ends during the austral fall. Figure 3 shows the distribution of SAMS onset and retreat dates in LENS and in observations for all available years. Note that each ensemble member of LENS represents 97 years and we have 40 members available; thus 3880 seasons are considered in LENS whereas we only have 36 seasons in CHIRPS. Generally, the SAMS onset date occurs later in the year in LENS than in observations. The mean onset date in LENS is 12 October, 19 days later than in observations (23 September). The SAMS retreat is earlier in the season in LENS by 21 days compared to observations (24 April and 15 May, respectively). When considering just the 1970-2000 period, the mean onset and retreat dates in LENS are 14 October and 23 April. The bias in the SAMS length in previous generation climate models (Bombardi et al. 2009) was linked to biases in the representation of the Atlantic ITCZ and rainfall over northern South America, as we discuss below. The later onset and earlier retreat of the wet season in LENS results in a shorter wet season in LENS than in observations. This may be a result of a dry bias that exists in LENS over most of South America. This dry bias is especially relevant over the northern and southern Amazon throughout the year. The mean and standard deviation of the precipitation bias in each region are shown in Table 1.

The precipitation bias of rainfall over South America is shown in Fig. S2. LENS overestimates rainfall over Nordeste during DJF, mainly due to a southern position of the ITCZ and a double ITCZ bias in the Atlantic. 
(a) Observations Before Onset

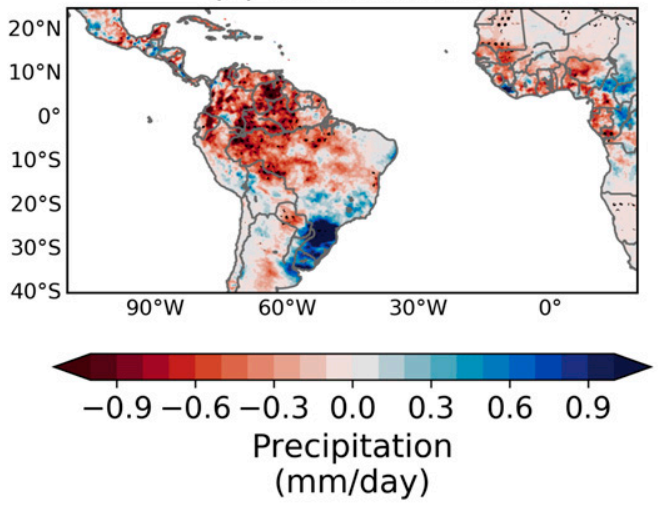

(b) LENS

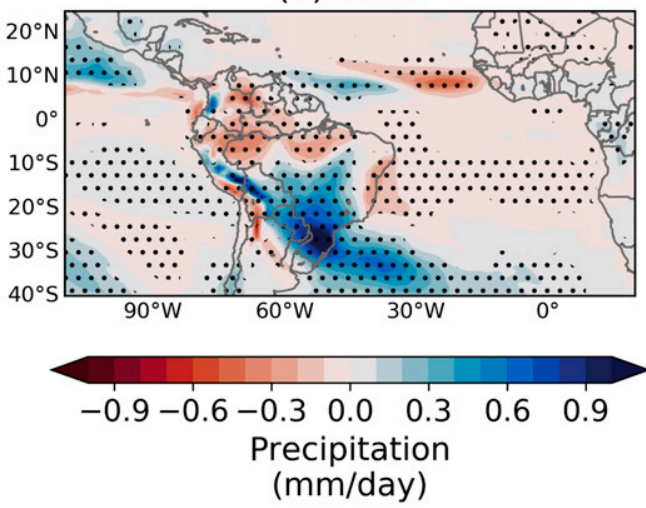

(c) Observations After Onset

(d) LENS
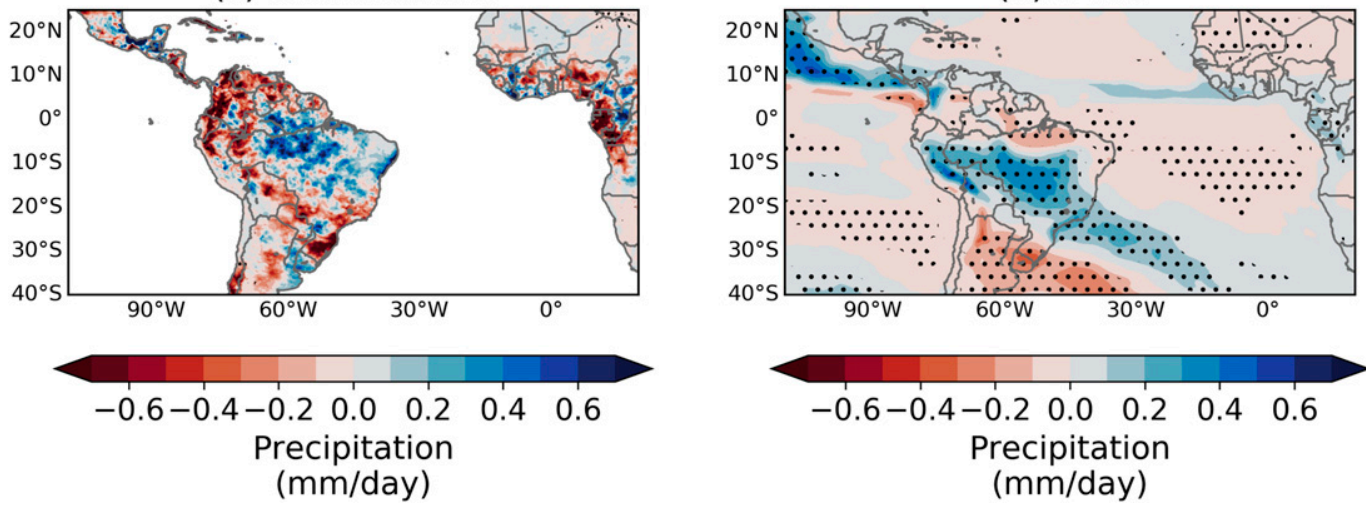

FIG. 5. (top) Rainfall anomaly of the daily mean rainfall averaged over 15 days immediately prior to SAMS onset in (a) CHIRPS and (b) LENS. (bottom) Rainfall anomaly averaged between 5 and 20 days after SAMS onset in (c) CHIRPS and (d) LENS. Stippled areas represent regions where the differences are statistically significant at or above the $95 \%$ confidence interval according to the $t$ test.

These biases exist in many CMIP5 climate models and have been linked to biases in meridional heat transport that originate from tropical and extratropical SST and cloud parameterization biases (Hawcroft et al. 2017; Li and Xie 2014; Adam et al. 2016, 2018).
LENS underestimates rainfall over the Amazon in all seasons, with stronger biases during the dry season. These biases have been linked to a too far south displaced ITCZ during JJA and during the transition to the wet season in the models. The southward displacement (a) Onset

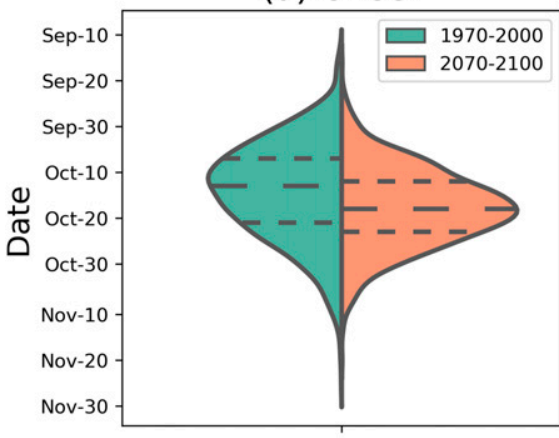

(b) Retreat

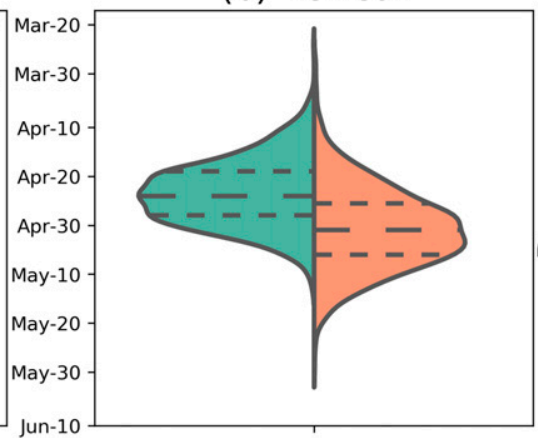

(c) Wet Season Length

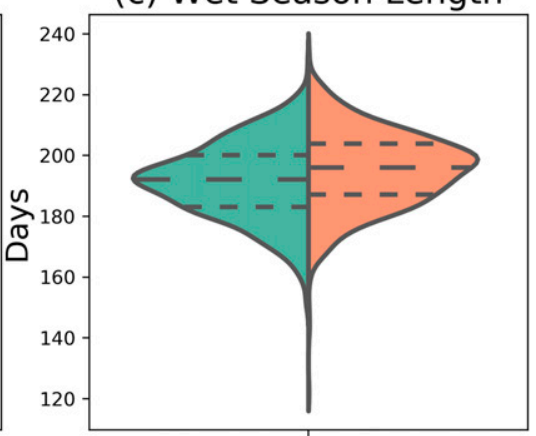

FIG. 6. Distribution of SAMS (a) onset date, (b) retreat date, and (c) wet-season length in the present (1970-2000; distribution on the left side of each panel; in green) and future (2070-2100; distribution on the right side of each panel; in orange) climate, in LENS. The mean of the distribution and the 25th and 75th percentiles are marked for each case. The distributions shown in each of the panels in this figure are significantly different according to the KS test. 

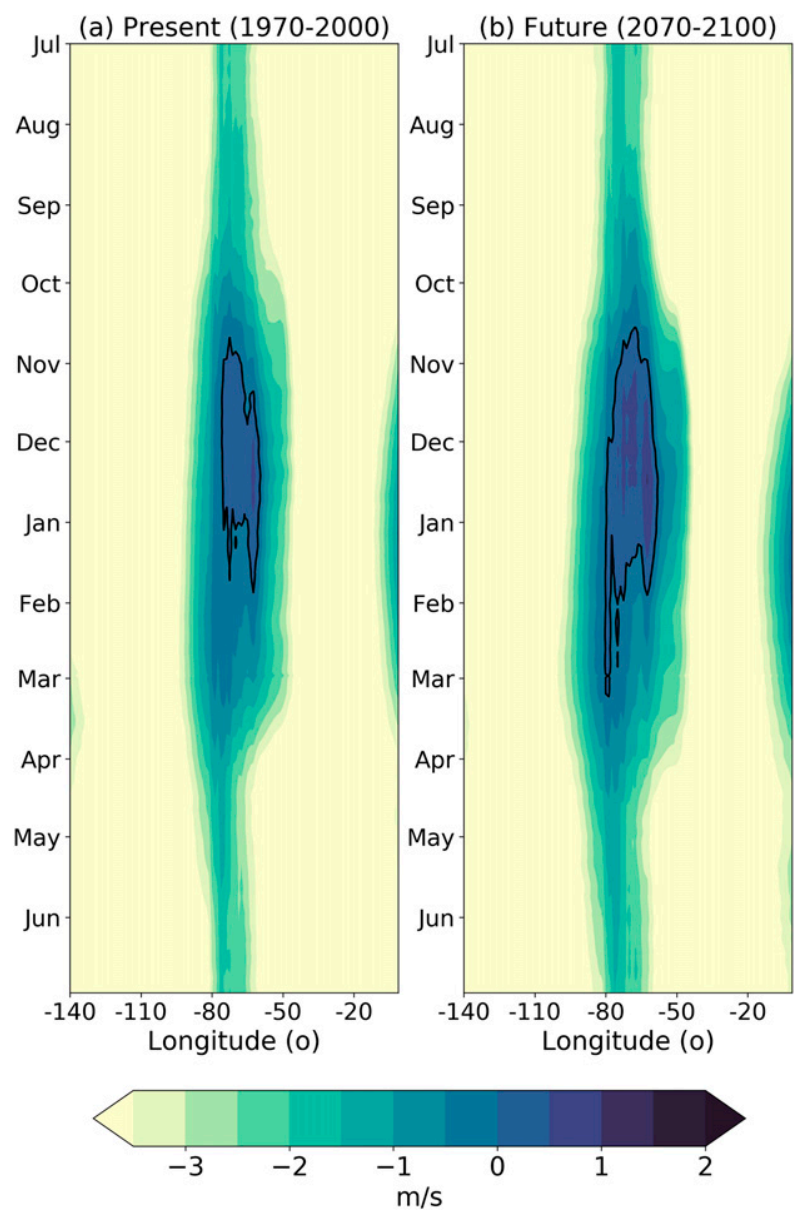

FIG. 7. Time evolution of the zonal wind at $850 \mathrm{hPa}$ averaged between $20^{\circ}$ and $5^{\circ} \mathrm{S}$ for longitudes $20^{\circ}-140^{\circ} \mathrm{W}$ in the (a) present and (b) future climate. The zero contour is marked in black.

of the ITCZ, in addition to a double ITCZ bias, displaces the Walker circulation, weakens the trade winds, and generates subsidence over the Amazon (Adam et al. 2018; Richter et al. 2014; Siongco et al. 2015). In LENS, there is a subsidence bias that inhibits deep convection over the Amazon (not shown). Another possible explanation for the dry bias over vegetated regions is a positive feedback in the land model to a lack of precipitation, with the soil moisture reacting unrealistically to drying (Sakaguchi et al. 2018; Lin et al. 2017). In an ensemble of climate models, Yin et al. (2013) showed that biases in evapotranspiration, Bowen ratio, cold-air intrusion, and the strength and position of the Pacific ITCZ can result in biases in rainfall over South America. Deep convective parameterization was also suggested to generate dry bias over the Amazon in the CESM model (Sakaguchi et al. 2018).

Despite a dry bias that is accentuated during the dry season, when we examine the seasonal cycle of precipitation, or the values after removing the annual mean, the seasonal cycle of precipitation is remarkably similar in LENS as in observations as seen in Fig. 4.

Even with the delay in SAMS onset, LENS is able to reproduce the large-scale spatial distribution of rainfall in the days preceding and following SAMS onset. Figures $5 \mathrm{a}$ and $5 \mathrm{~b}$ show a composite of the mean daily rainfall anomaly over South America 15 days immediately before SAMS onset for observations and the ensemble mean of LENS. The same is shown for the mean daily rainfall anomaly 5 to 20 days after SAMS onset in Figs. $5 \mathrm{c}$ and $5 \mathrm{~d}$. Prior to SAMS onset, the observed rainfall anomaly is negative over the Amazon. Meanwhile, the rainfall anomalies over southern Brazil are positive before SAMS onset (Fig. 5a). After SAMS onset, this rainfall dipole switches signs (Fig. 5c). Rainfall increases over the Amazon, while southern Brazil becomes dryer. This signal relates to compensating subsidence related to the establishment of the heat source over the SACZ, and is one of the main features of the SAMS onset, as shown in earlier studies (Gandu and Silva Dias 1998; Raia and Cavalcanti 2008). LENS successfully reproduces this rainfall dipole, both before and after onset (Figs. 5b,d). This dipole-like pattern is related to the moisture transport by the SALLJ (Marengo et al. 2012). In the period leading up to SAMS onset, there is an increase in moisture transport to southern Brazil, contributing to rainfall over the region. After SAMS onset, moisture transport from the Amazon to southeastern Brazil increases, establishing favorable conditions for the development of the SACZ.

Overall, there is a good agreement between the seasonality and spatial distribution of rainfall over South America in LENS, reanalysis, and observations. This is especially encouraging in light of the significant bias in total rainfall in the region that was discussed above.

\section{b. Future projections of SAMS}

Now that we have established that LENS can simulate important characteristics of the SAMS, we analyze how SAMS precipitation and wet-season length are projected to change. Figure 6 shows the distribution of the SAMS onset date, retreat date, and length in current climate and by the end of the twenty-first century. There is a delay both in the mean onset date and retreat date of 3 and 7 days, respectively. As a result, the average wet season lengthens by about 4 days. All differences are significant according to the Kolmogorov-Smirnov test.

The delay in SAMS retreat is associated with a longer persistence of the SALLJ over South America. Figure 7 shows the evolution of the 850 -hPa zonal wind in the tropical $\left(20^{\circ}\right.$ to $\left.5^{\circ} \mathrm{S}\right)$ South America and adjacent oceans (longitude sector $20^{\circ}$ to $140^{\circ} \mathrm{W}$ ) for present and future climate. From late October, the mean flow is dominated 
(a) July to September

(i) Present (1970-2000)

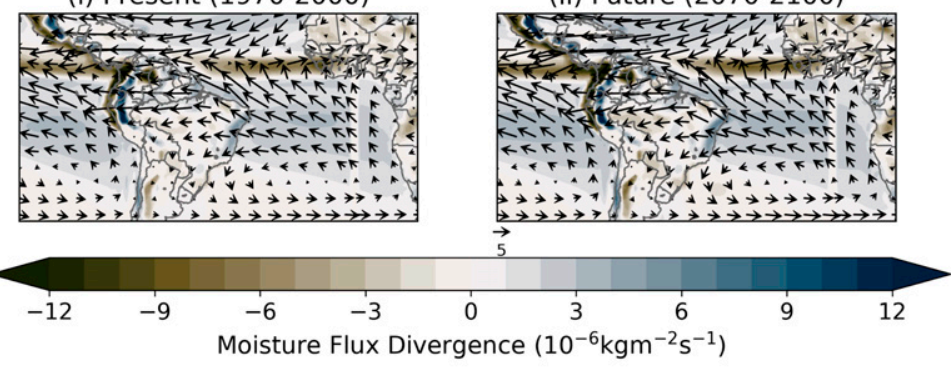

(b) October to December

(i) Present (1970-2000)

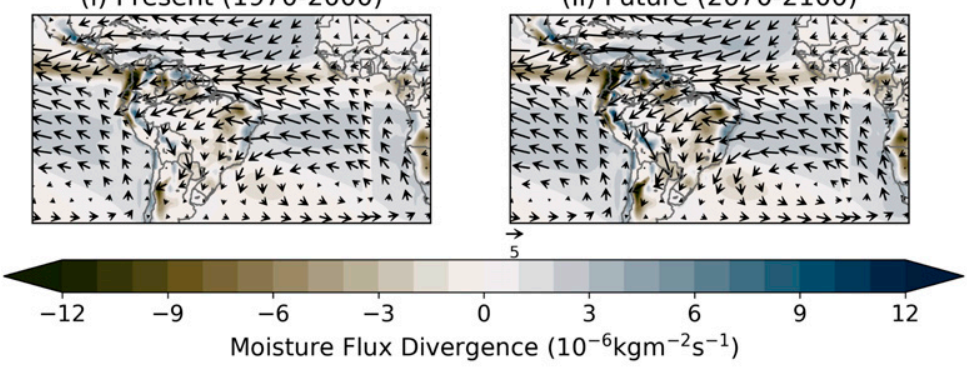

(c) January to March

(i) Present (1970-2000)

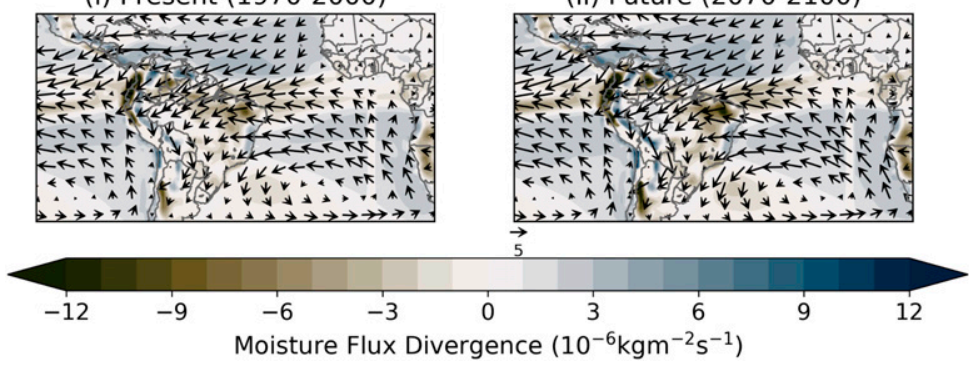

(iii) Future - Present

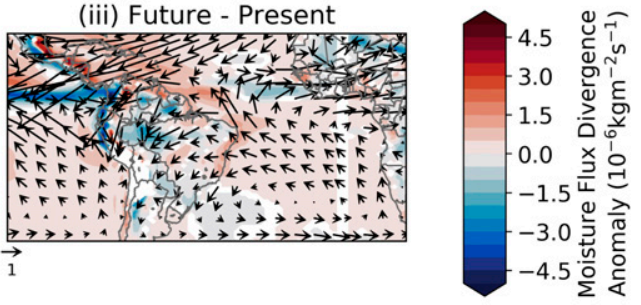

(iii) Future - Present

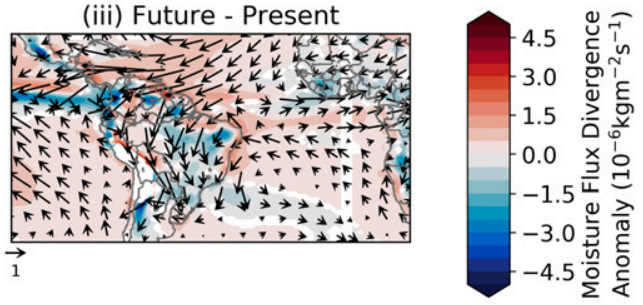

FIG. 8. Ensemble-mean vertically integrated moisture flux (arrows) and its divergence (color shading) averaged over (a) July to September, (b) October to December, and (c) January to March for (left) present climate and (center) future climate, and (right) the difference between future and present climate in LENS. The statistical significance of the moisture flux anomalies at or above the 95\% confidence interval was calculated using the $t$ test. The anomalies of the moisture flux are only shown where at least one component is significant. Areas where the moisture divergence anomalies are not significant are shown in white in the right column.

by westerly winds, that spread eastward as the wet season evolves. This represents the development and evolution of the SALLJ. In the future period, the westerly 850-hPa zonal wind becomes more pronounced over the SAMS development area and throughout the wet season, suggesting a more robust SALLJ. This is especially relevant during the late wet season, when the westerlies remain active for longer in future climate, and delay SAMS retreat. Along the cross section highlighted in Fig. 1, the ensemble average for the future has a westerly anomaly of the zonal component of the 850 -hPa wind that is $0.76 \mathrm{~m} \mathrm{~s}^{-1}$ stronger when compared to present during the month of April, which is the most common month for SAMS retreat in LENS. In fact, the zonal component of the wind becomes more westerly in all seasons analyzed with the exception of the transition to the wet season (averaged between July and September), when there is a strengthening of the easterlies over the area. This result is consistent with the delay in the beginning of the wet season, as shown in Fig. 6. Moreover, the total wind speed significantly increases for all seasons except for the beginning of the dry season (averaged between April and June), when it remains the same. The increase in wind speed in the future climate ranges from 0.36 (January to March) and $0.59 \mathrm{~m} \mathrm{~s}^{-1}$ (July to September). It is important to note that the westerly winds are underestimated in the model when compared to ERA-Interim.

As the SALLJ strengthens, it also carries more moisture to continental South America. Due to thermodynamical 
(a) JFM
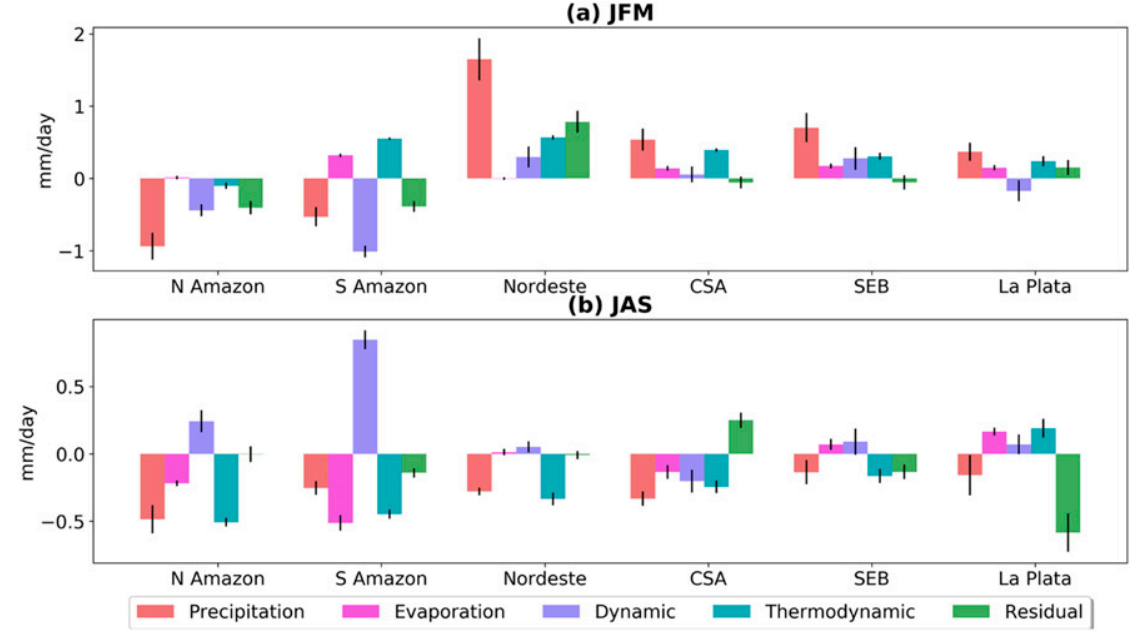

FIG. 9. Ensemble-mean precipitation change in future climate and the contributions to that from the terms in the budget equation due to change in dynamic, thermodynamic, and evaporation components in each area averaged during (a) January to March and (b) July to September.

effects, the future atmosphere is able to hold more moisture and there is an increase in the total moisture carried by the winds. Prior to the transition to the wet season [JulySeptember (JAS)], the vertically integrated moisture flux from the tropical Atlantic to the Amazon is increased in the future, generating more moisture convergence over the region (Fig. 8a). As the wet season develops [OctoberDecember (OND) and January-March (JFM)], a stronger, wetter SALLJ carries more moisture from the Amazon to the subtropics. As a result, more moisture reaches the continent, especially in the areas corresponding to CSA, SEB, and La Plata (Figs. 8b,c).

Meanwhile, the SASH weakens in future climate (not shown), contributing to increased moisture flux to the continent, also partially due to increased evaporation over the South Atlantic. As a result, there is an increase in moisture influx from the South Atlantic Ocean into SEB. The confluence of the moisture from the SASH and SALLJ contributes to the formation of the South Atlantic convergence zone. Figure 9a shows the contributions of the evaporation, dynamic, and thermodynamic terms to the changes in rainfall during the peak of the wet season [see the budget terms in Eqs. (2)-(4)]. We can see that the thermodynamic term contributes the most to the increased rainfall over SEB and CSA, followed closely by the dynamic term in SEB.

Finally, we find that the ITCZ gets narrower in future climate over the Atlantic, with rainfall intensifying at its center during the wet season. Moisture convergence increases over Nordeste during the wet season (not shown), as the area receives more moisture both from the northern and southern tropical Atlantic (Fig. 8c), increasing rainfall over the northern and western portions of the Nordeste region, especially during JFM. Meanwhile, rainfall over the east coast of the region decreases, due to the narrowing of the ITCZ and the increased subsidence associated with the strengthening of the ITCZ at its center.

The wet-season rainfall increases over Nordeste, CSA, SEB, and La Plata and it is the main source of the increase in the annual mean rainfall over those areas (Fig. 10a). Meanwhile, there is less precipitation during the late dry season (JAS; Fig. 10b) in all of the areas analyzed. This suggests that in a warmer climate those areas will become even more dependent on the wet-season strength, with consequences for water and energy management. Another consequence of these projections is the increase in frequency and strength of extreme events of rainfall, as we will show in section $3 \mathrm{c}$.

A different pattern emerges over the Amazon with drying in all seasons. This drying has consequences for rain forest productivity over the region. As the region receives less rainfall, the total water storage over land is reduced over the Amazon (Fig. 11a). As the vegetation activity over the southern Amazon is water-limited, the mean net primary productivity (NPP) over the area is reduced during the late dry season (Fig. 11b). The mean NPP over the southern Amazon not only decreases but also changes sign, and the region becomes a net carbon source. As soil moisture and forest productivity are 
(a) Annual

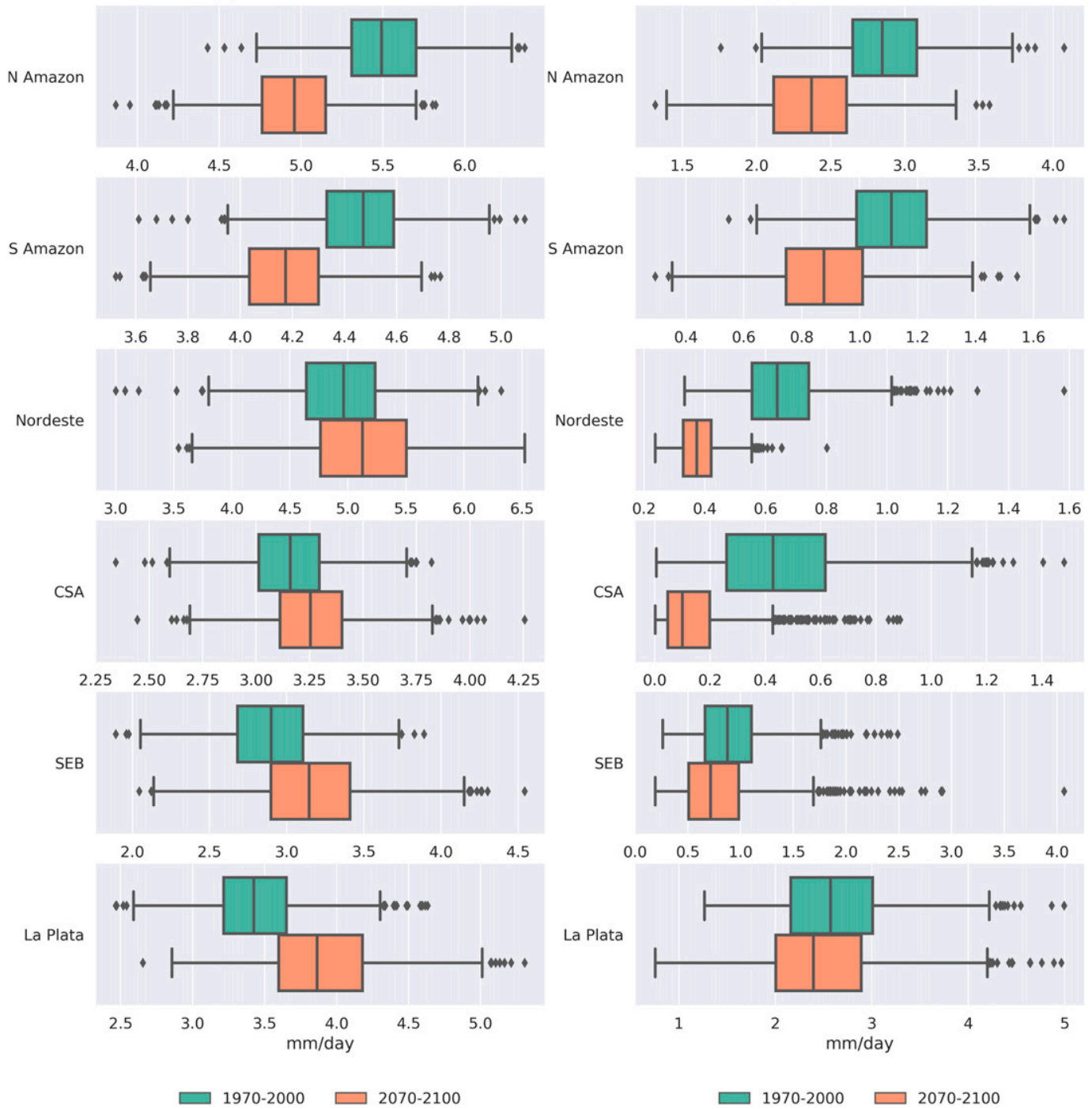

FIG. 10. Distribution of the present (1970-2000; in green) and future (2070-2100; in orange) mean (a) annual and (b) July to September precipitation $\left(\mathrm{mm} \mathrm{day}^{-1}\right)$ in LENS. The distributions shown in each of the panels are significantly different according to the KS test.

reduced, so is the surface latent heat flux over the northeastern South America (Fig. 11c). An analysis of the relative contributions of the thermodynamic and dynamic effects in the precipitation response shows that the change in evaporation and moisture is responsible for the relative drying of the southern Amazon region during JAS, while the dynamics attenuates this effect, due to the wind convergence over the area (Fig. 9b). As the wet season is delayed, the rising motion associated with deep convection over the Amazon is reduced during the wet season. As the deep convection over the Amazon decreases, so does the compensating subsidence over southern Brazil and Paraguay, contributing to increased rainfall over the La Plata Basin area during the early wet season (OND; Fig. 11d).

\section{c. Extreme events of rainfall}

As rainfall both increases during the wet season and decreases during the dry season, extreme rainfall events are also affected in future climate. In this section, we analyze the projected changes in the extreme events distribution in LENS by the end of the twenty-first century.

Figure 12 shows the time evolution of the maximum number of consecutive dry days in a year and for each region. Due to its dry bias during the dry season, LENS 

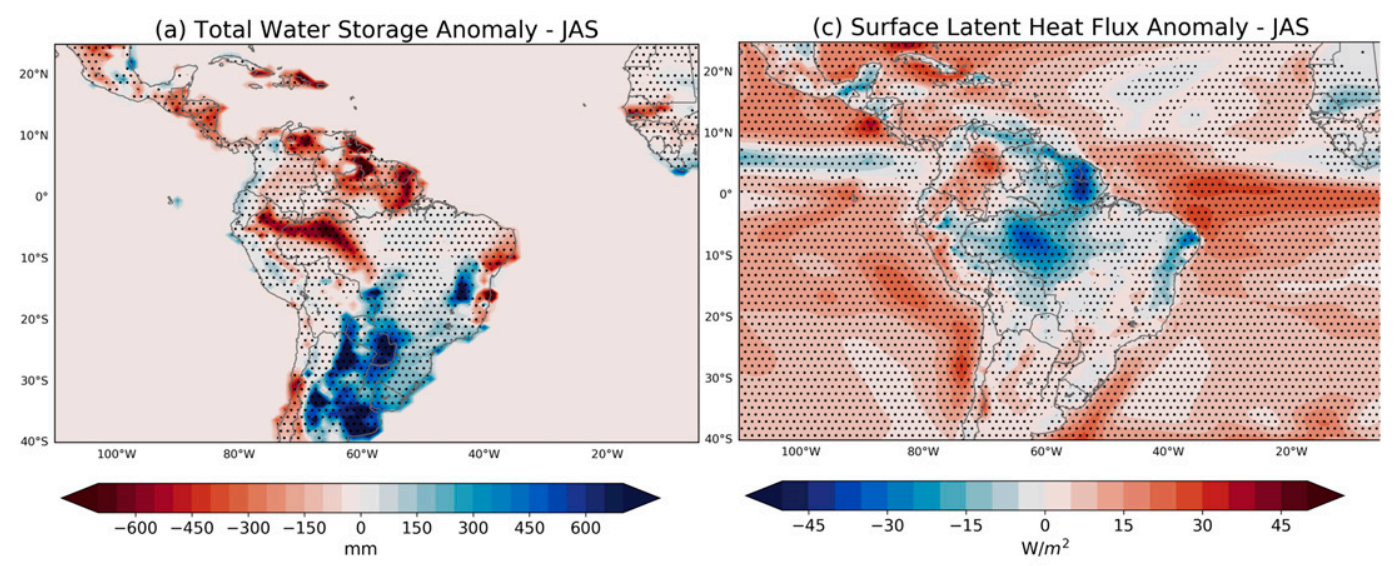

(b) NPP-JAS

(d) Vertical Velocity at 500hPa Anomaly - OND

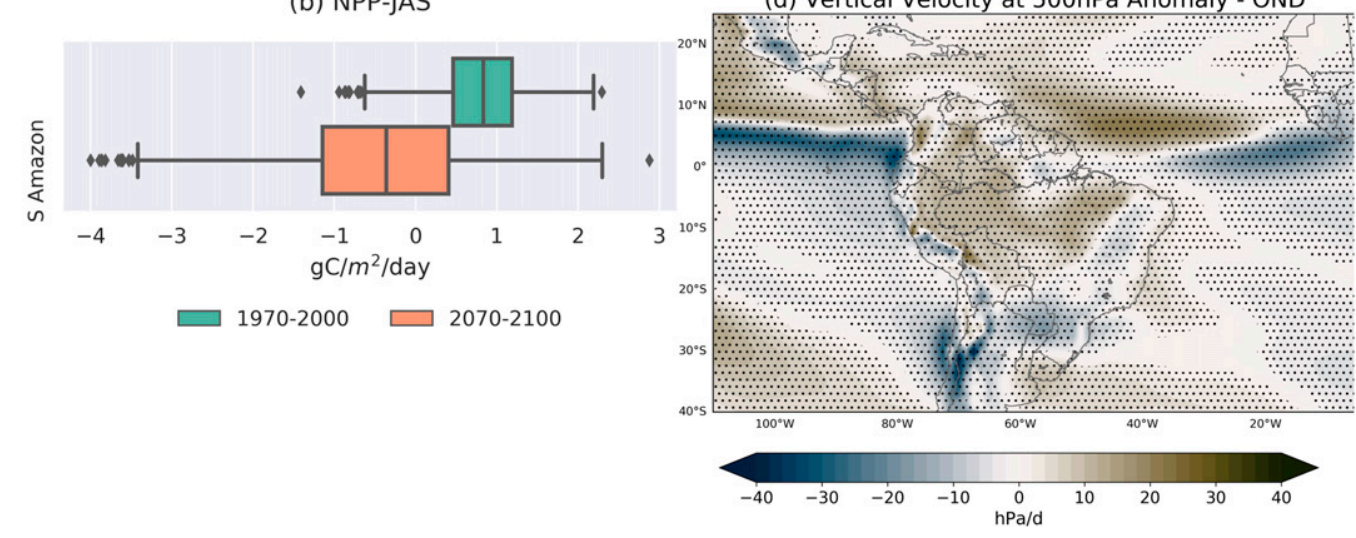

FIG. 11. (a) Ensemble-mean difference of total water storage between future and present climate for July to September in LENS. (b) Distribution of the mean net primary production over the southern Amazon in July to September for the present (in green) and future (in orange) in LENS. These distributions are significantly different according to the KS test. (c) Ensemble-mean difference in surface latent heat flux between future and present climate for July to September in LENS. (d) Ensemble-mean difference in vertical velocity at the 500-hPa pressure surface between future and present climate for October to December in LENS. Stippled areas represent regions where the differences are statistically significant at or above the $95 \%$ confidence interval according to the $t$ test in (a), (c), and (d).

overestimates the number of consecutive dry days over South Amazon, Nordeste, and CSA. In a warmer climate, extreme dry periods become significantly longer for all the regions analyzed, except La Plata and S Amazon, where there is no significant change in the future when compared to the present. For N Amazon, where the dry period is less intense, the maximum number of consecutive dry days increases from 13 days in the present to 35 days $\mathrm{yr}^{-1}$ in the future climate. Over northeastern Brazil, a region already affected by drought in present climate, the mean number of consecutive dry

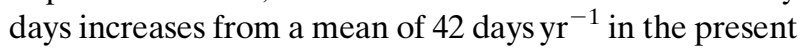
to 100 days $\mathrm{yr}^{-1}$ in the future. Note that increased temperature will intensify the effects of dry periods.

Meanwhile, the extreme wet days become more frequent and extreme in all regions analyzed. Figure 13 shows the probability density functions of the maximum daily precipitation for each region analyzed. The location parameters of all the distributions are shifted to the right, suggesting an increase in the most common value. Meanwhile, the scale parameter also increases, suggesting that the distribution spreads in the future, and favors greater values. This increase in the extreme wet days is especially clear for Nordeste (Fig. 13c) and La Plata (Fig. 13f).

\section{Summary and conclusions}

In this paper we analyzed future projection of the South American monsoon system, as well as precipitation in specific areas of South America in the CESM Large Ensemble. 


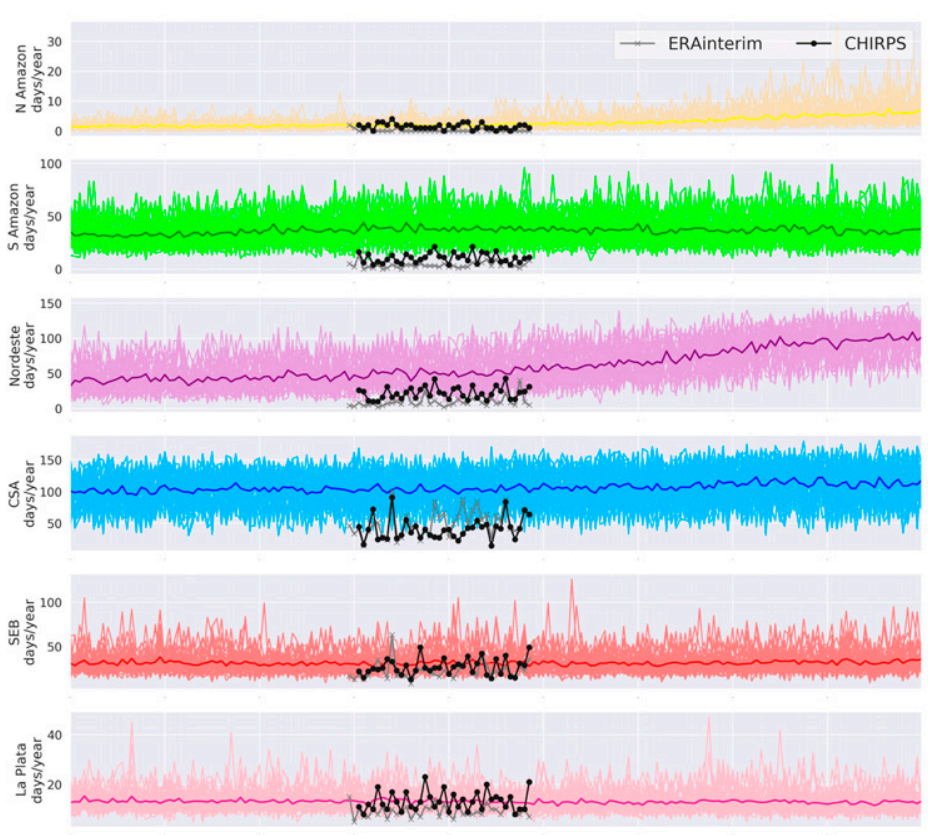

(a)

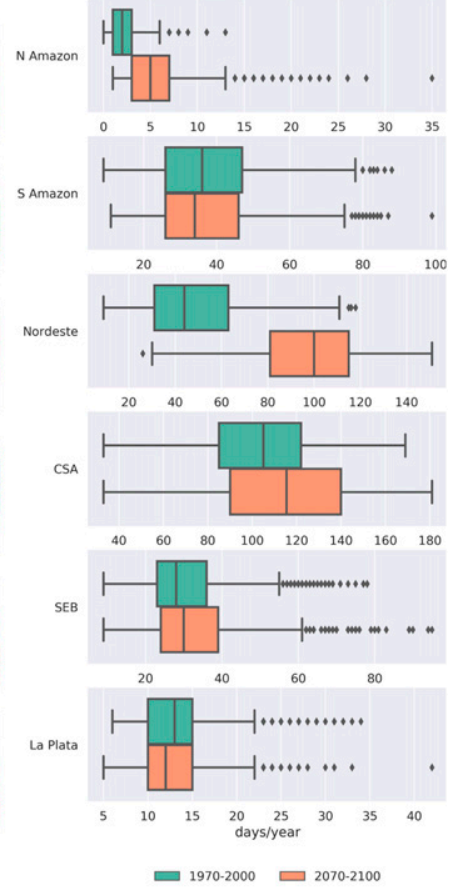

(b)

FIG. 12. (a) Evolution of the annual maximum number of consecutive dry days for each area in ERA-Interim (in gray), CHIRPS (in black), and LENS (colors). Each ensemble member is depicted, and the ensemble mean is highlighted by a bold contour. (b) Distribution of the annual maximum number of consecutive dry days for the present (in green) and future (in orange) climate for each area. The distributions are significantly different according to the KS test for North Amazon, Nordeste, CSA, and SEB.

Both the onset and retreat of the South American monsoon are delayed in future climate. Since the SALLJ remains active for longer during the transition to the dry season, the averaged date of SAMS retreat is delayed by 7 days. SAMS onset is also delayed by 3 days, mostly due to local processes, such as the decrease in latent heat release over the southern Amazon during the transition to the wet season. The net effect is a modest but significant increase in the length of the wet season. Note that the mean date of SAMS onset in LENS is 19 days later in the season and the mean retreat in LENS occurs 21 days earlier in the season when compared to observations.

Although the length of the SAMS wet season increases, the Amazon becomes dryer in all seasons. The increase in atmospheric $\mathrm{CO}_{2}$ generally increases the rain forest's net primary productivity through carbon fertilization; however, this process is water limited. During the peak of the dry season, the drying over the southern Amazon reduces the total water storage in the soil and NPP is reduced, making the area a net carbon source.

When interpreting these results, it is important to note that rainfall over the Amazon is underestimated by LENS, and there is a known positive feedback between lack of rainfall, soil moisture, and temperature. CESM has this bias over the Amazon, and that is one possible reason for the dry rainfall biases in the region (Sakaguchi et al. 2018). Since soil moisture is known to mediate the impacts of drought caused by El Niño into the dry season (Levine et al. 2019), the effects of this bias on the rainfall trends should be addressed in future studies. Moreover, important components for estimating the forest activity in the future are not included in most climate models. For example, phosphorus is an important limiting nutrient over large parts of the Amazon, and its low availability limits $\mathrm{CO}_{2}$ fertilization (Fleischer et al. 2019; Yang et al. 2014).

The lengthening of SAMS, as well as the increase in moisture influx by the SALLJ and SASH into southeastern and central Brazil, results in an increase in wet-season rainfall over those regions. Rainfall also increases over northeastern Brazil during the wet season, as the ITCZ over the tropical Atlantic intensifies and narrows equatorward in future climate, increasing rainfall at the northwestern portion of the region during JFM, while rainfall over Nordeste's eastern coast is reduced due to an increase in the associated subsidence. Meanwhile, the dry season gets dryer in all of the regions 
(a) N Amazon

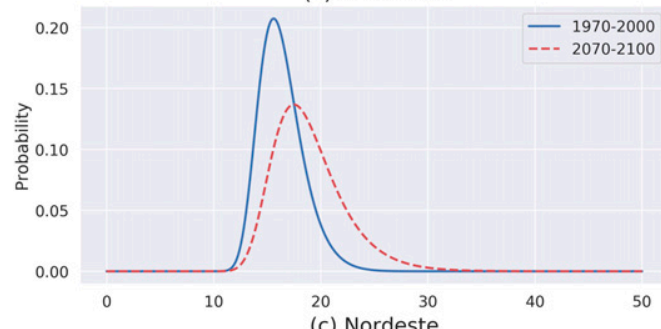

(c) Nordeste

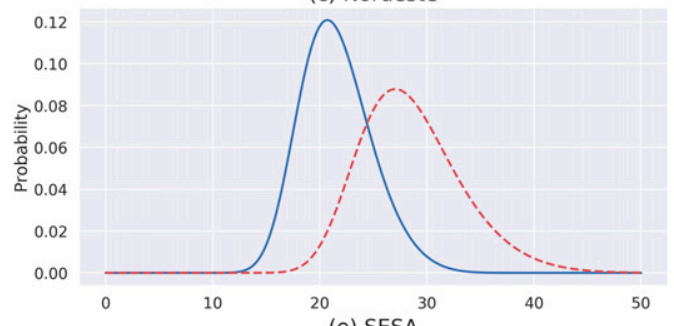

(e) SESA

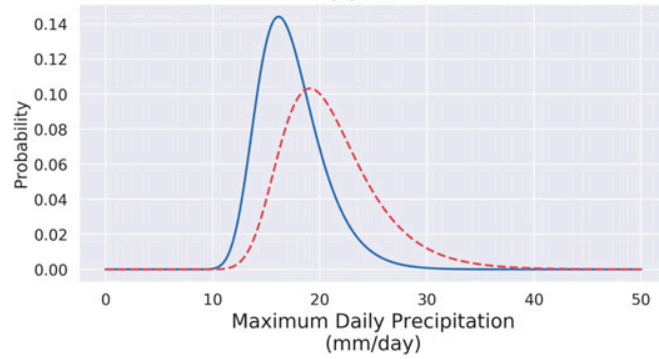

(b) S Amazon
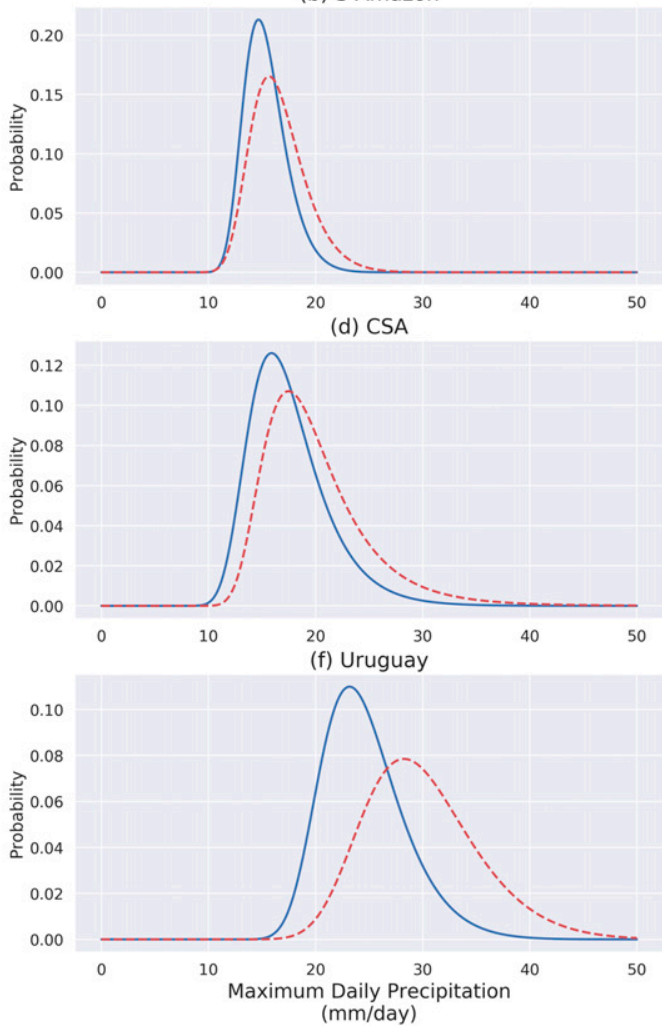

FIG. 13. Probability density function of the annual maximum area-averaged daily precipitation. A GEV distribution was fitted for the present (1970-2000; in blue), and future climate (2070-2100; in red) for the (a) northern Amazon, (b) southern Amazon, (c) northeastern Brazil, (d) central South America, (e) southeastern Brazil, and (f) La Plata Basin regions. All the distributions are significantly different according to the KS test.

analyzed, and thus these regions will depend more on the wet season's rainfall. While previous studies (Seth et al. 2013) related the delay of SAMS onset to a decrease in moisture convergence over South America in austral spring, this was not found to be the case in LENS. An increase in moisture transport from the Atlantic Ocean to South America was found in the spring, and the delay in SAMS onset is mostly related to local processes, due to the decreased latent heat release over the rain forest.

Extreme rainfall events become more frequent in future climate. Wet events become more frequent and extreme in future climate for all regions analyzed, and dry events become longer and more frequent by the end of the twenty-first century. The northern Amazon, which in the present climate has virtually no dry periods in LENS, sees a significant increase in meteorological drought occurrence in future climate. The dry events are further exasperated by increased temperature in future climate. Northeastern Brazil is a particularly interesting area, registering an increase in both dry and wet extreme events, along with a greater dependence on wet-season rainfall in future climate. The results from this study have important consequences for vegetation dynamics and fire occurrence, as well as effects on waterway transportation and water and electricity supply.

Acknowledgments. We acknowledge the CESM Large Ensemble Project and the National Center for Atmospheric Research Computational and Information Systems Laboratory for providing access to the data. We thank three anonymous reviewers for their suggestions and comments. This project is supported by the NASA Earth and Space Science Fellowship, Grant 80NSSC17K0386, National Science Foundation Grant AGS-1624038, and Department of Energy Grant DE-SC0019407.

\section{REFERENCES}

Adam, O., T. Schneider, F. Brient, and T. Bischoff, 2016: Relation of the double-ITCZ bias to the atmospheric energy budget in 
climate models. Geophys. Res. Lett., 43, 7670-7677, https:// doi.org/10.1002/2016GL069465.

,-- , and — 2018: Regional and seasonal variations of the double-ITCZ bias in CMIP5 models. Climate Dyn., 51, 101117, https://doi.org/10.1007/s00382-017-3909-1.

Agudelo, J., P. A. Arias, S. C. Vieira, and J. A. Martínez, 2019: Influence of longer dry seasons in the southern Amazon on patterns of water vapor transport over northern South America and the Caribbean. Climate Dyn., 52, 2647-2665, https://doi.org/ 10.1007/s00382-018-4285-1.

Boers, N., N. Marwan, H. M. J. Barbosa, and J. Kurths, 2017: A deforestation-induced tipping point for the South American monsoon system. Sci. Rep., 7, 41489, https://doi.org/10.1038/srep41489.

Boisier, J. P., P. Ciais, A. Ducharne, and M. Guimberteau, 2015: Projected strengthening of Amazonian dry season by constrained climate model simulations. Nat. Climate Change, $\mathbf{5}$, 656-660, https://doi.org/10.1038/nclimate2658.

Bombardi, R. J., A. E. Leila, and M. V. Carvalho, 2009: IPCC global coupled model simulations of the South America monsoon system. Climate Dyn., 33, 893-916, https://doi.org/ 10.1007/s00382-008-0488-1.

Carvalho, L. M. V., C. Jones, and B. Liebmann, 2002: Extreme precipitation events in southeastern South America and largescale convective patterns in the South Atlantic convergence zone. J. Climate, 15, 2377-2394, https://doi.org/10.1175/15200442(2002)015<2377:EPEISS >2.0.CO;2.

,-- , and -2004 : The South Atlantic convergence zone: Intensity, form, persistence, and relationships with intraseasonal to interannual activity and extreme rainfall. J. Climate, 17, 88-108, https://doi.org/10.1175/1520-0442(2004) 017<0088:TSACZI > 2.0.CO;2.

Coelho, C. A., and Coauthors, 2016: The 2014 southeast Brazil austral summer drought: Regional scale mechanisms and teleconnections. Climate Dyn., 46, 3737-3752, https://doi.org/ 10.1007/s00382-015-2800-1.

Collini, E. A., E. H. Berbery, V. R. Barros, and M. E. Pyle, 2008: How does soil moisture influence the early stages of the South American monsoon? J. Climate, 21, 195-213, https://doi.org/ 10.1175/2007JCLI1846.1.

Cook, B. I., J. E. Smerdon, R. Seager, and S. Coats, 2014: Global warming and 21 st century drying. Climate Dyn., 43, 2607-2627, https://doi.org/10.1007/s00382-014-2075-y.

Dee, D. P., and Coauthors, 2011: The ERA-Interim reanalysis: Configuration and performance of the data assimilation system. Quart. J. Roy. Meteor. Soc., 137, 553-597, https://doi.org/ 10.1002/qj.828.

Donat, M. G., A. L. Lowry, L. V. Alexander, P. A. O'Gorman, and N. Maher, 2016: More extreme precipitation in the world's dry and wet regions. Nat. Climate Change, 6, 508-513, https:// doi.org/10.1038/nclimate2941.

Duffy, P. B., P. Brando, G. P. Asner, and C. B. Field, 2015: Projections of future meteorological drought and wet periods in the Amazon. Proc. Natl. Acad. Sci. USA, 112, 13 172-13 177, https://doi.org/10.1073/pnas.1421010112.

Endo, H., and A. Kitoh, 2014: Thermodynamic and dynamic effects on regional monsoon rainfall changes in a warmer climate. Geophys. Res. Lett., 41, 1704-1711, https://doi.org/10.1002/ 2013 GL059158.

Feldpausch, T. R., and Coauthors, 2016: Amazon forest response to repeated droughts. Global Biogeochem. Cycles, 30, 964-982, https://doi.org/10.1002/2015GB005133.

Figueroa, S. N., P. Satyamurty, and P. L. Da Silva Dias, 1995: Simulations of the summer circulation over the South American region with an eta coordinate model. J. Atmos. Sci., 52, 1573-1584, https://doi.org/ 10.1175/1520-0469(1995)052<1573:SOTSCO >2.0.CO;2.

Fleischer, K., and Coauthors, 2019: Amazon forest response to $\mathrm{CO}_{2}$ fertilization dependent on plant phosphorus acquisition. Nat. Geosci., 12, 736-741, https://doi.org/10.1038/s41561-0190404-9.

Fu, R., and Coauthors, 2013: Increased dry-season length over southern Amazonia in recent decades and its implication for future climate projection. Proc. Natl. Acad. Sci. USA, 110, 18110-18115, https://doi.org/10.1073/pnas.1302584110.

Funk, C., and Coauthors, 2015: The Climate Hazards Infrared Precipitation with Stations-A new environmental record for monitoring extremes. Sci. Data, 2, 150066, https://doi.org/ 10.1038/sdata.2015.66.

Gan, M. A., V. B. Rao, and M. C. L. Moscati, 2005: South American monsoon indices. Atmos. Sci. Lett., 6, 219-223, https://doi.org/10.1002/asl.119.

Gandu, A. W., and P. L. Silva Dias, 1998: Impact of tropical heat sources on the South American tropospheric upper circulation and subsidence. J. Geophys. Res., 103, 6001-6015, https:// doi.org/10.1029/97JD03114.

Grimm, A. M., 2019: South American monsoon and its extremes. Tropical Extremes: Natural Variability and Trends, Elsevier, 51-93, https://doi.org/10.1016/B978-0-12-809248-4.00003-0.

Hawcroft, M., J. M. Haywood, M. Collins, A. Jones, A. C. Jones, and G. Stephens, 2017: Southern Ocean albedo, interhemispheric energy transports and the double ITCZ: Global impacts of biases in a coupled model. Climate Dyn., 48, 22792295, https://doi.org/10.1007/s00382-016-3205-5.

Haylock, M. R., and Coauthors, 2006: Trends in total and extreme South American rainfall in 1960-2000 and links with sea surface temperature. J. Climate, 19, 1490-1512, https://doi.org/ 10.1175/JCLI3695.1.

Jones, C., and L. M. V. Carvalho, 2013: Climate change in the South American monsoon system: Present climate and CMIP5 projections. J. Climate, 26, 6660-6678, https://doi.org/10.1175/ JCLI-D-12-00412.1.

Kay, J. E., and Coauthors, 2015: The Community Earth System Model (CESM) large ensemble project: A community resource for studying climate change in the presence of internal climate variability. Bull. Amer. Meteor. Soc., 96, 1333-1349, https://doi.org/10.1175/BAMS-D-13-00255.1.

Kotz, S., and S. Nadarajah, 2010: Generalized extreme value distributions. Extreme Value Distributions, Imperial College Press, 61-93, https://doi.org/10.1142/9781860944024_0002.

Lehner, F., S. Coats, T. F. Stocker, A. G. Pendergrass, B. M. Sanderson, C. C. Raible, and J. E. Smerdon, 2017: Projected drought risk in $1.5^{\circ} \mathrm{C}$ and $2{ }^{\circ} \mathrm{C}$ warmer climates. Geophys. Res. Lett., 44, 7419-7428, https://doi.org/10.1002/2017GL074117.

Levine, P. A., J. T. Randerson, Y. Chen, M. S. Pritchard, M. Xu, and F. M. Hoffman, 2019: Soil moisture variability intensifies and prolongs eastern Amazon temperature and carbon cycle response to El Niño-Southern Oscillation. J. Climate, 32, 1273-1292, https://doi.org/10.1175/JCLI-D-18-0150.1.

Lewis, S. L., P. M. Brando, O. L. Phillips, G. M. F. van der Heijden, and D. Nepstad, 2011: The 2010 Amazon drought. Science, 331, 554, https://doi.org/10.1126/science.1200807.

Li, G., and S.-P. Xie, 2014: Tropical biases in CMIP5 multimodel ensemble: The excessive equatorial Pacific cold tongue and double ITCZ problems. J. Climate, 27, 1765-1780, https:// doi.org/10.1175/JCLI-D-13-00337.1.

Lin, Y., W. Dong, M. Zhang, Y. Xie, W. Xue, J. Huang, and Y. Luo, 2017: Causes of model dry and warm bias over central U.S. and 
impact on climate projections. Nat. Commun., 8, 881, https:// doi.org/10.1038/s41467-017-01040-2.

Mahli, Y., and Coauthors, 2009: Exploring the likelihood and mechanism of a climate-change-induced dieback of the Amazon rainforest. Proc. Natl. Acad. Sci. USA, 106, 20 610-20 615, https:// doi.org/10.1073/pnas.0804619106.

Marengo, J. A., and Coauthors, 2012: Recent developments on the South American monsoon system. Int. J. Climatol., 32, 1-21, https://doi.org/10.1002/joc.2254.

—- M. Valverde, and G. Obregon, 2013: Observed and projected changes in rainfall extremes in the metropolitan area of São Paulo. Climate Res., 57, 61-72, https://doi.org/10.3354/ cr01160.

Pascale, S., L. M. V. Carvalho, D. K. Adams, C. L. Castro, and I. F. A. Cavalcanti, 2019: Current and future variations of the monsoons of the Americas in a warming climate. Curr. Climate Change Rep., 5, 125-144, https://doi.org/10.1007/ s40641-019-00135-w.

Phillips, O. L., and Coauthors, 2009: Drought sensitivity of the Amazon rainforest. Science, 323, 1344-1347, https://doi.org/ 10.1126/science. 1164033 .

Raia, A., and I. F. A. Cavalcanti, 2008: The life cycle of the South American monsoon system. J. Climate, 21, 6227-6246, https:// doi.org/10.1175/2008JCLI2249.1.

Richter, I., S. P. Xie, S. K. Behera, T. Doi, and Y. Masumoto, 2014: Equatorial Atlantic variability and its relation to mean state biases in CMIP5. Climate Dyn., 42, 171-188, https://doi.org/ 10.1007/s00382-012-1624-5.

Sakaguchi, K., L. R. Leung, C. D. Burleyson, H. Xiao, and H. Wan, 2018: Role of troposphere-convection-land coupling in the southwestern Amazon precipitation bias of the Community Earth System Model version 1 (CESM1). J. Geophys. Res. Atmos., 123, 8374-8399, https://doi.org/ 10.1029/2018jd028999.

Seth, A., S. A. Rauscher, M. Biasutti, A. Giannini, S. J. Camargo, and M. Rojas, 2013: CMIP5 projected changes in the annual cycle of precipitation in monsoon regions. J. Climate, 26, 73287351, https://doi.org/10.1175/JCLI-D-12-00726.1.
Siongco, A. C., C. Hohenegger, and B. Stevens, 2015: The Atlantic ITCZ bias in CMIP5 models. Climate Dyn., 45, 1169-1180, https://doi.org/10.1007/s00382-014-2366-3.

Skansi, M. M., and Coauthors, 2013: Warming and wetting signals emerging from analysis of changes in climate extreme indices over South America. Global Planet. Change, 100, 295-307, https://doi.org/10.1016/j.gloplacha.2012.11.004.

Trenberth, K. E., and C. J. Guillemot, 1995: Evaluation of the global atmospheric moisture budget as seen from analyses. J. Climate, 8, 2255-2272, https://doi.org/10.1175/15200442(1995)008<2255:EOTGAM >2.0.CO;2.

Vera, C., and Coauthors, 2006: Toward a unified view of the American monsoon systems. J. Climate, 19, 4977-5000, https:// doi.org/10.1175/JCLI3896.1.

Wright, J. S., R. Fu, J. R. Worden, S. Chakraborty, N. E. Clinton, C. Risi, Y. Sun, and L. Yin, 2017: Rainforest-initiated wet season onset over the southern Amazon. Proc. Natl. Acad. Sci., 114, 8481-8486, https://doi.org/10.1073/ pnas.1621516114.

Xu, L., A. Wang, D. Wang, and H. Wang, 2019: Hot spots of climate extremes in the future. J. Geophys. Res. Atmos., 124, 3035-3049, https://doi.org/10.1029/2018jd029980.

Yang, J., H. Tian, S. Pan, G. Chen, B. Zhang, and S. Dangal, 2018: Amazon drought and forest response: Largely reduced forest photosynthesis but slightly increased canopy greenness during the extreme drought of 2015/2016. Global Change Biol., 24, 1919-1934, https://doi.org/10.1111/gcb.14056.

Yang, X., P. E. Thornton, D. M. Ricciuto, and W. M. Post, 2014: The role of phosphorus dynamics in tropical forests-A modeling study using CLM-CNP. Biogeosciences, 11, 16671681, https://doi.org/10.5194/bg-11-1667-2014.

Yin, L., R. Fu, E. Shevliakova, and R. E. Dickinson, 2013: How well can CMIP5 simulate precipitation and its controlling processes over tropical South America? Climate Dyn., 41, 3127-3143, https://doi.org/10.1007/s00382-012-1582-y.

Zhou, J., and K. M. Lau, 1998: Does a monsoon climate exist over South America? J. Climate, 11, 1020-1040, https://doi.org/ 10.1175/1520-0442(1998)011<1020:DAMCEO > 2.0.CO;2. 